\title{
Photovoltaic and Amplified Spontaneous Emission Studies of High-Quality Formamidinium Lead Bromide Perovskite Films
}

\author{
Neha Arora, M. Ibrahim Dar, * Mahmoud Hezam, Wolfgang Tress, Gwénolé Jacopin, \\ Thomas Moehl, Peng Gao, Abdulah Saleh Aldwayyan, Benoit Deveaud, Michael Grätzel, \\ and Mohammad Khaja Nazeeruddin**
}

This study demonstrates the formation of extremely smooth and uniform formamidinium lead bromide $\left(\mathrm{CH}\left(\mathrm{NH}_{2}\right)_{2} \mathrm{PbBr}_{3}=\mathrm{FAPbBr}_{3}\right)$ films using an optimum mixture of dimethyl sulfoxide and $\mathrm{N}, \mathrm{N}$-dimethylformamide solvents. Surface morphology and phase purity of the $\mathrm{FAPbBr}_{3}$ films are thoroughly examined by field emission scanning electron microscopy and powder X-ray diffraction, respectively. To unravel the photophysical properties of these films, systematic investigation based on time-integrated and timedependent photoluminescence studies are carried out which, respectively, bring out relatively lower nonradiative recombination rates and long lasting photogenerated charge carriers in $\mathrm{FAPbBr}_{3}$ perovskite films. The devices based on $\mathrm{FTO} / \mathrm{TiO}_{2} / \mathrm{FAPbBr}_{3}$ /spiro-OMeTAD/Au show highly reproducible open-circuit voltage $\left(V_{\text {oc }}\right)$ of $1.42 \mathrm{~V}$, a record for $\mathrm{FAPbBr}_{3}$-based perovskite solar cells. $V_{\text {oc }}$ as a function of illumination intensity indicates that the contacts are very selective and higher $V_{\text {oc }}$ values are expected to be achieved when the quality of the $\mathrm{FAPbBr}_{3}$ film is further improved. Overall, the devices based on these films reveal appreciable power conversion efficiency of 7\% under standard illumination conditions with negligible hysteresis. Finally, the amplified spontaneous emission (ASE) behavior explored in a cavity-free configuration for $\mathrm{FAPbBr}_{3}$ perovskite films shows a sharp ASE threshold at a fluence of $190 \mu \mathrm{J} \mathrm{cm}^{-2}$ with high quantum efficiency further confirming the high quality of the films.

\section{Introduction}

The growing demand for renewable energy has brought solar cells to the forefront as a potential energy harvester. Consequently, organic-inorganic metal halide perovskite solar cells have garnered profound research interest in recent years as next-generation photovoltaics. ${ }^{[1]}$ This importance stems largely from their exceptional charge carrier mobilities, and optical and electronic properties that are tunable by varying the chemical composition. ${ }^{[2,3]}$ Recently, perovskite-based solar cells have demonstrated an impressive power conversion efficiency (PCE) of over $20 \% .{ }^{[4]}$ In most of the practical applications of solar cells, besides the importance of short-circuit current density, high open-circuit voltage $\left(V_{\text {oc }}\right)$ is an indispensable parameter to attain both high power conversion efficiency with reduced series resistance losses and to drive electrochemical reactions including watersplitting reactions and $\mathrm{CO}_{2}$ reduction. ${ }^{[5,6]}$ In principle, a high open-circuit voltage in a perovskite solar cell can be attained by aligning the energy levels of absorber and charge extraction layers. ${ }^{[7]}$ Despite having enticing benefit of higher bandgap for pure bromide-based perovskite material

M. Hezam

King Abdullah Institute for Nanotechnology

King Saud University

Riyadh 11451, Saudi Arabia

M. Hezam, Dr. G. Jacopin, Prof. B. Deveaud

Laboratory of Quantum Optoelectronics Institute of Physics

École Polytechnique Fédérale de Lausanne

Lausanne $\mathrm{CH}-1015$, Switzerland

Prof. A. S. Aldwayyan

Physics and Astronomy Dept, Photonics Lab

College of Science

King Saud University

Riyadh 11451, Saudi Arabia
Lausanne $\mathrm{CH}-1015$, Switzerland

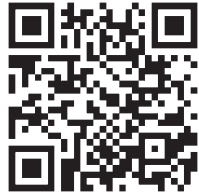

Dr. M. I. Dar, Dr. W. Tress, Dr. T. Moehl,

Laboratory of Photonics and Interfaces

Institute of Chemical Sciences and Engineering

DOI: $10.1002 / \mathrm{adfm} .201504977$ 
which indeed can also be used as a top cell in tandem solar cells, ${ }^{[8]}$ much of the research mainly focused on pure iodide $\left(\mathrm{CH}_{3} \mathrm{NH}_{3} \mathrm{PbI}_{3}\right)$, mixed halide $\left(\mathrm{CH}_{3} \mathrm{NH}_{3} \mathrm{PbI}_{3-x} \mathrm{Br}_{x}\right)$ or doublemixed $\left(\left(\mathrm{CH}\left(\mathrm{NH}_{2}\right)_{2} \mathrm{PbI}_{3}\right)_{1-x}\left(\mathrm{CH}_{3} \mathrm{NH}_{3} \mathrm{PbBr}_{3}\right)_{x}\right)$ perovskites. ${ }^{[4]}$ Nevertheless, promising studies on efficient methylammonium lead bromide $\left(\mathrm{CH}_{3} \mathrm{NH}_{3} \mathrm{PbBr}_{3}\right)$-based device architecture showing enhanced photovoltage in comparison to pure iodidebased perovskite have been documented. Kojima et al. reported on employing $\mathrm{CH}_{3} \mathrm{NH}_{3} \mathrm{PbBr}_{3}$ as visible-light sensitizers in photoelectrochemical cells exhibiting a promising photovoltage of $0.96 \mathrm{~V}$ with a power conversion efficiency of $3.1 \% .{ }^{[9]}$ Later on, Edri et al. demonstrated a high $V_{\text {oc }}$ of $1.3 \mathrm{~V}$ based on alumina। $\mathrm{CH}_{3} \mathrm{NH}_{3} \mathrm{PbBr}_{3} \backslash N, N^{\prime}$-dialkyl perylenediimide (PDI) solar cell structure, however the efficiency of the devices was quite low $(<1 \%) .{ }^{[10]}$ Recently, by controlling the crystallization process of $\mathrm{CH}_{3} \mathrm{NH}_{3} \mathrm{PbBr}_{3}$ as well as by tailoring the highest occupied molecular orbital (HOMO) levels of different hole-transporting materials (HTMs), a $V_{\text {oc }}$ of $1.51 \mathrm{~V}$ has been reported. ${ }^{[11]}$

So far, most of the studies on bromide perovskites are devoted to $\mathrm{CH}_{3} \mathrm{NH}_{3} \mathrm{PbBr}_{3}$, however, the focus of this work constitutes formamidinium lead bromide $\left(\mathrm{CH}\left(\mathrm{NH}_{2}\right)_{2} \mathrm{PbBr}_{3}=\right.$ $\mathrm{FAPbBr}_{3}$ ) perovskite which has been studied scantly. Earlier, Hanusch et al. described the fabrication of planar heterojunction $\mathrm{FAPbBr}_{3}$ perovskite solar cells with efficiency of over $6 \%,{ }^{[12]}$ however, the device exhibited severe hysteresis which leads to an overestimation of power conversion efficiency. Mostly the presence of mesoporous $\mathrm{TiO}_{2}$ scaffold has proven to be advantageous in reducing the scan speed dependent hysteresis observed in current-voltage $(J-V)$ curves in perovskite solar cells. ${ }^{[13,14]}$ Tuning the growth of perovskite structures has been one of the critical parameters to fabricate high-efficiency solar cells. To that end, we investigated the role of solvent on the growth and morphology of $\mathrm{FAPbBr}_{3}$ perovskite films, which eventually led to the enhancement in the photovoltage to a remarkable extent. We fabricated $\mathrm{FAPbBr}_{3}$ films employing the sequential deposition method involving a mixture of solvents, $N, N$-dimethylformamide and dimethyl sulfoxide(DMF+DMSO) for the $\mathrm{PbBr}_{2}$ precursor solution. Employing spiro-OMeTAD as a hole-transporting material led us to fabricate $\mathrm{FAPbBr}_{3}$ perovskite devices with a $J_{\mathrm{sc}}$ of $6.8 \mathrm{~mA} \mathrm{~cm}^{-2}, \mathrm{FF}$ of $72 \%$, and $V_{\mathrm{oc}}$ of $1.42 \mathrm{~V}$ resulting in an overall efficiency of $7.0 \%$. It is to be noted that these devices exhibited negligible hysteresis. The impact of the solvent on structural, morphological, and various photophysical properties which dictate the photovoltaic performance of a device was explored by X-ray diffraction (XRD), field emission scanning electron microscopy (FESEM), UV-visible absorption, low temperature photoluminescence (PL), and charge carrier lifetime studies.

Additionally, amplified spontaneous emission (ASE) was recorded from the $\mathrm{FAPbBr}_{3}$ perovskite films. Recently, there has been a report in which formamidinium lead bromide perovskite nanoparticles were incorporated into light-emitting electrochemical cells. ${ }^{[15]}$ In the literature various studies have demonstrated the enormous potential of perovskite materials as optical gain mediums even with a cavity-free configuration. ${ }^{[16,17]}$ The low nonradiative recombination rate, long diffusion length, and high mobility of charge carriers reported for perovskites even with high defect trap densities, are key factors for their unprecedented progress in photovoltaics. ${ }^{[18-20]}$
In addition to slow Auger recombination, the various possibilities of fabricating them in different cavity configurations make them suitable for an efficient semiconductor laser. ${ }^{[21-23]}$ In this work, a sharp transition from spontaneous emission (SE) to ASE at a pump fluence of $190 \mu \mathrm{J} \mathrm{cm}^{-2}$ per pulse was observed in $\mathrm{FAPbBr}_{3}$ perovskite films which corresponds to an ASE threshold carrier density of $\approx 2.3 \times 10^{18} \mathrm{~cm}^{-3}$. Although ASE has been reported for both $\mathrm{CH}_{3} \mathrm{NH}_{3} \mathrm{PbI}_{3}$ and $\mathrm{CH}_{3} \mathrm{NH}_{3} \mathrm{PbBr}_{3}$ perovskites in different resonating and cavity-free configurations as well as in random networks of nanocrystals, ${ }^{[16,17,21-23]}$ to the best of our knowledge, there has been no report till date demonstrating the light gain applications of such $\mathrm{FAPbBr}_{3}$ perovskite films.

\section{Results and Discussion}

Two different $\mathrm{FAPbBr}_{3}$ perovskite films were deposited using the sequential deposition approach. Typically, a solution of $\mathrm{PbBr}_{2}$ (DMF) or $\mathrm{PbBr}_{2}$ (DMF+DMSO) was spin casted onto a mesoporous $\mathrm{TiO}_{2}$ scaffold. Subsequently the resulting films were converted into $\mathrm{FAPbBr}_{3}$ perovskite films by dipping into isopropanol solution of formamidinium bromide $\left(\mathrm{CH}\left(\mathrm{NH}_{2}\right)_{2} \mathrm{Br}\right)$, which were labeled as $\mathbf{F A}(\mathbf{1})$ (obtained from $\mathrm{PbBr}_{2}(\mathrm{DMF})$ ) and $\mathrm{FA}(2)$ (obtained from $\mathrm{PbBr}_{2}$ (DMF+DMSO)). (See the Experimental Section for more details.)

\subsection{Structural and Morphological Characterization}

To evaluate the crystallinity of $\mathbf{F A}(\mathbf{1})$ and $\mathbf{F A}(\mathbf{2})$ perovskite films, $\mathrm{X}$-ray diffraction was performed at room temperature. The XRD patterns (Figure S1, Supporting Information) obtained from the films could be indexed to the cubic phase of $\mathrm{FAPbBr}_{3}$ with a space group $P m-3 m$, which is consistent with previous reports. ${ }^{[12,15]}$

The morphology of lead bromide and $\mathrm{FAPbBr}_{3}$ films was probed by FESEM. From SEM analysis, it is evident that coverage of the lead bromide films obtained from $\mathrm{PbBr}_{2}$ (DMF) (Figure 1a) solution is relatively poor whereas the deposition of $\mathrm{PbBr}_{2}$ (DMF+DMSO) solution led to the formation of a uniform lead bromide film (Figure 1b). Furthermore, top view SEM micrograph of FA(1) perovskite sample reveals the formation of an inhomogeneous film composed of aggregated $\mathrm{FAPbBr}_{3}$ structures (Figure 1c). On the contrary, extremely uniform and continuous $\mathrm{FAPbBr}_{3}$ films with full surface coverage were obtained in case of FA(2), as shown in Figure 1d. From a marked difference in the surface morphology of lead bromide and $\mathrm{FAPbBr}_{3}$ films for $\mathrm{FA}(1)$ and $\mathrm{FA}(2)$ samples, we establish that the nature of the solvent employed for $\mathrm{PbBr}_{2}$ precursor solution can considerably improve the surface coverage of the films, which ostensibly could be beneficial for the fabrication of efficient devices. ${ }^{[13]}$

The device fabrication was completed by spin coating spiroOMeTAD as the hole-transporting material on $\mathrm{FAPbBr}_{3}$ perovskite layer, followed by thermal evaporation of a $70 \mathrm{~nm}$ thick gold layer as a back contact. The cross-section SEM micrograph of FA(1) (Figure 1e) shows the formation of a nonuniform $\mathrm{FAPbBr}_{3}$ film of $\approx 500 \mathrm{~nm}$ thickness (including mesoporous $\mathrm{TiO}_{2}$ ). 

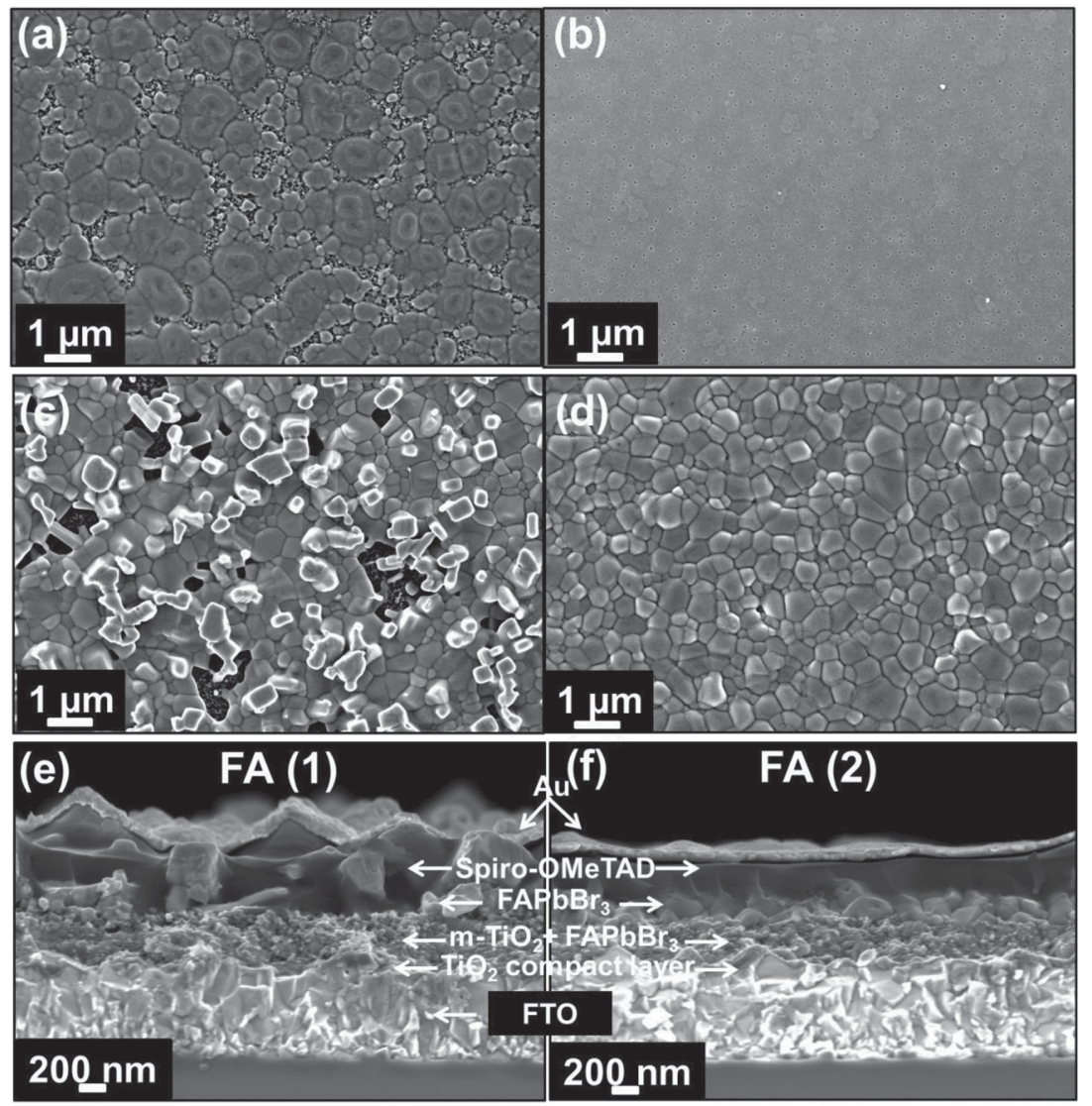

Figure 1. Scanning electron microscopy analysis. Top view of a) $\mathrm{PbBr}_{2}$ (DMF), b) $\mathrm{PbBr}_{2}$ (DMF+DMSO) films, c) $\mathrm{FA}(1)$ : $\mathrm{FAPbBr}{ }_{3}$ perovskite films prepared from $\mathrm{PbBr}_{2}$ (DMF), d) $\mathrm{FA}(2)$ : $\mathrm{FAPbBr}_{3}$ perovskite films prepared from $\mathrm{PbBr}_{2}$ (DMF+DMSO). Cross-sectional SEM image of devices based on e) $F A(1)$ and f) $F A(2)$ films.

From the top view and cross-section SEM analysis, parasitic contacts between organic conductor (HTM) and the mesoporous $\mathrm{TiO}_{2}$ layer as well as between pillared perovskite layer and top gold contact are observed. Expectedly, a mixture of solvents (DMF+DMSO) yields smoother and continuous $\mathrm{FAPbBr}_{3}$ film with a uniform thickness of $\approx 300 \mathrm{~nm}$, which is homogeneously covered with spiro-OMeTAD (Figure 1f).

From a detailed SEM analysis, we noticed that using a mixture of solvents (DMF+DMSO) for lead bromide precursor solution resulted in the formation of smoother films. ${ }^{[24-26]}$ In addition to enhancement in solubility, mixed solvents possibly slow down the growth of lead halide structures during spin coating, yielding a uniform film (Figure 1b). ${ }^{[27]}$ Low boiling solvent (DMF) evaporates rapidly and eventually enhances the loading (Figure 1e) whereas because of slower evaporation of high boiling solvent (DMSO), discontinuous and less loaded lead bromide and $\mathrm{FAPbBr}_{3}$ films are formed, as evident from SEM and UV-visible spectrum (Figures S2,S3, Supporting Information). Smoother $\mathrm{FAPbBr}_{3}$ film with an optimum thickness could warrant the fabrication of efficient perovskite solar cells. Therefore, to tailor the formation and loading of $\mathrm{FAPbBr}_{3}$ structures, it became imperative to use a judicious ratio of low and high boiling solvents. As is known DMSO solvent has a tendency to form an adduct with lead iodide or it could pronounce the amorphous nature of lead iodide films. ${ }^{[27,28]}$ Using DMSO-lead iodide adduct, the fabrication of high-efficiency solar cells has been reported recently. ${ }^{[4,28]}$ To understand the role of DMSO further, we recorded XRD patterns of FA(1) and FA(2) lead bromide films. Variation in the crystal structure of lead bromide films deposited from a single and a stoichiometric mixture of DMF+DMSO solvent (Figure S4, Supporting Information) was marginal which is in contrast to what has been observed in lead iodide films. ${ }^{[27]}$

\subsection{Photovoltaic Properties of Formami- dinium Perovskite Devices}

Tailoring the growth and morphology of perovskite layer is one of the critical factors that led to the evolution of high-efficiency perovskite solar cells. Herein, we investigated the effect of morphology of $\mathrm{FAPbBr}_{3}$ films on the performance of the resulting devices. The current-voltage curves of the FA(1) and FA(2) bromide perovskite devices are shown in Figure 2 and the extracted photovoltaic parameters are summarized in Table 1. Under illumination of $100 \mathrm{~mW} \mathrm{~cm} \mathrm{~cm}^{-2}$, the device based on $\mathbf{F A}(\mathbf{1})$ film $\left(\mathrm{FAPbBr}_{3}\right.$ film involving $\mathrm{PbBr}_{2}$ (DMF) precursor solution), exhibits a high short-circuit current density $\left(J_{\mathrm{sc}}\right)$ of $7.1 \mathrm{~mA} \mathrm{~cm}^{-2}$, a modest open-circuit voltage $V_{\text {oc }}$ of $1.14 \mathrm{~V}$, and a fill factor $(\mathrm{FF})$ of 0.67 , resulting in an overall power conversion efficiency $(\eta)$ of $5.4 \%$ (Figure $2 \mathrm{a}$ ). By contrast, FA(2) device exhibits similar short-circuit current density $\left(U_{\mathrm{sc}}\right)$ of $6.8 \mathrm{~mA}$ $\mathrm{cm}^{-2}$, a record $V_{\text {oc }}$ for formamidinium perovskite of $1.42 \mathrm{~V}$, and a FF of 0.72 , resulting in an overall conversion efficiency $(\eta)$ of $7.0 \%$ (Figure $2 \mathrm{~b}$ ). Ostensibly, a higher $J_{\mathrm{sc}}$ value of $7.1 \mathrm{~mA} \mathrm{~cm} \mathrm{~m}^{-2}$ obtained from FA(1) device could be due to the formation of thicker $\mathrm{FAPbBr}_{3}$ films as evident from cross-sectional SEM analysis (Figure 1e). By changing the solvent from DMF to a stoichiometric mixture of DMF+DMSO solvents for the $\mathrm{PbBr}_{2}$ precursor solution, $V_{\text {oc }}$ increases significantly from 1.14 to $1.42 \mathrm{~V}$ which demonstrates that the morphology of the film has a considerable impact on the photovoltage.

\subsubsection{Insight into the Origin of High $V_{o c}$}

The $V_{\text {oc }}>1.4 \mathrm{~V}$ for $\mathbf{F A}(2)$ devices is extraordinarily high considering the contact materials $\mathrm{FTO} / \mathrm{TiO}_{2}$ and spiro-OMeTAD. Assuming that the work function of the $\mathrm{FTO} / \mathrm{TiO}_{2}$ is $\approx-4.0$ to $-4.2 \mathrm{eV}$ and the HOMO in the doped spiro-OMeTAD at $-5.4 \mathrm{eV}$ and, thus, the work function close but smaller than this value, $V_{\text {oc }}$ is larger than the built-in potential. ${ }^{[29]}$ Therefore, the energetics of the contact materials do not merely define the $V_{\text {oc }}$ as commonly reported in the literature. ${ }^{[30,31]}$ Such a high $V_{\text {oc }}$ is 


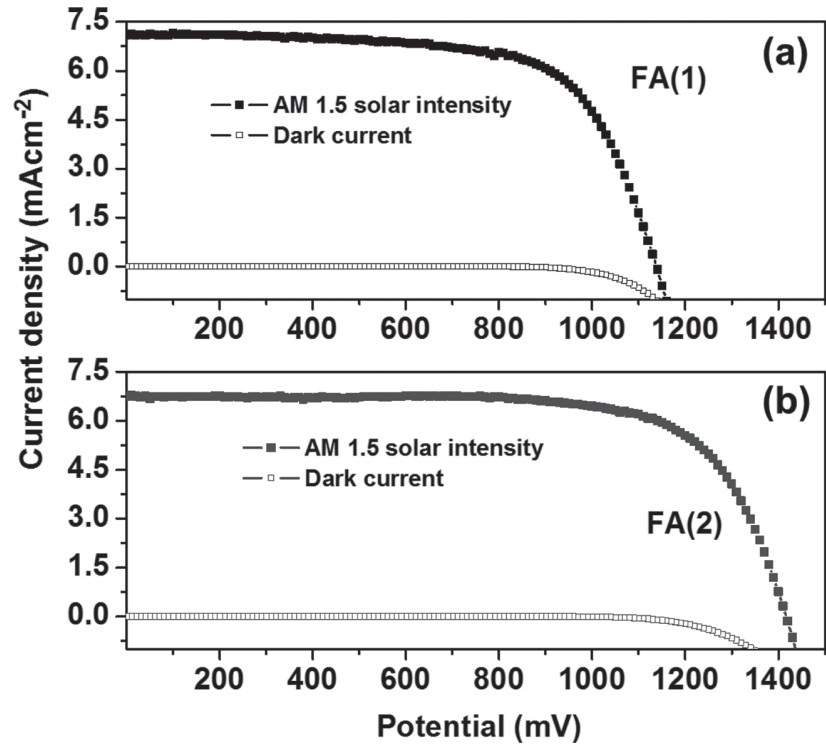

Figure 2. Photovoltaic performance of perovskite devices with spiroOMeTAD as hole transporter recorded at a scan rate of $0.1 \mathrm{~V} \mathrm{~s}^{-1}$ under simulated AM1.5 $100 \mathrm{~mW} \mathrm{~cm}{ }^{-2}$ photon flux. a) $\mathrm{FA}(1)$ : $\mathrm{FAPbBr}_{3}$ perovskite device prepared from $\mathrm{PbBr}_{2}$ (DMF) and b) $\mathrm{FA}(2)$ : $\mathrm{FAPbBr}$. device prepared from $\mathrm{PbBr}_{2}$ (DMF+DMSO) solution.

only possible when free charge carrier generation occurs within the perovskite itself, i.e., interfaces to $\mathrm{TiO}_{2}$ or spiro-OMeTAD are not required to split excitons. Additionally, recombination of photogenerated holes at FTO and electrons at spiro-OMeTAD has to be suppressed, i.e., contacts have to be selective. In that case, $V_{\mathrm{oc}}$ is determined by the equilibrium between carrier generation and recombination in the absorber itself, which defines the splitting of electron and hole quasi Fermi level. Given a sufficient diffusivity, charges are driven by diffusion towards their respective electrodes to generate photocurrent for voltages close to but smaller than $V_{\mathrm{oc}}$.

To get a closer insight into the recombination mechanisms limiting $V_{\text {oc }}$, we measured $V_{\text {oc }}$ as a function of illumination intensity. ${ }^{[32]}$ The data shown in Figure 3 with a slope of $120 \mathrm{mV} /$ decade indicate that $V_{\text {oc }}$ is determined by recombination via defects. Even at 1 sun, the slope is not decreased, which would be expected for limitations by surface recombination in case of a compensated built-in potential for large $V_{\text {oc }}{ }^{[32]}$ This indicates that the contacts are very selective and $V_{\text {oc }}$ continues increasing for higher light intensities. In particular, spiro-OMeTAD does not seem to limit $V_{\text {oc }}$ and higher $V_{\text {oc }}$ values may be reached when the quality of the $\mathrm{FAPbBr}_{3} / \mathrm{TiO}_{2}$ film is further improved, i.e., the defect density reduced, while maintaining the contact materials. The high selectivity of the device structure is given by offsets in the valence band of $\mathrm{TiO}_{2}$ and the lowest occupied

Table 1. Summarized photovoltaic parameters derived from currentvoltage curves for the FA(1) and FA(2) devices fabricated using different precursor solution of $\mathrm{PbBr}_{2}$.

\begin{tabular}{lcccc}
\hline Sample & $J_{\mathrm{sc}}\left[\mathrm{mA} \mathrm{cm}^{-2}\right]$ & $V_{\mathrm{oc}}[\mathrm{V}]$ & $\mathrm{FF}[\%]$ & $\mathrm{PCE}[\%]$ \\
\hline $\mathrm{FA}(1)$ & 7.1 & 1.14 & 67 & 5.4 \\
$\mathrm{FA}(2)$ & 6.8 & 1.42 & 72 & 7.0 \\
\hline
\end{tabular}

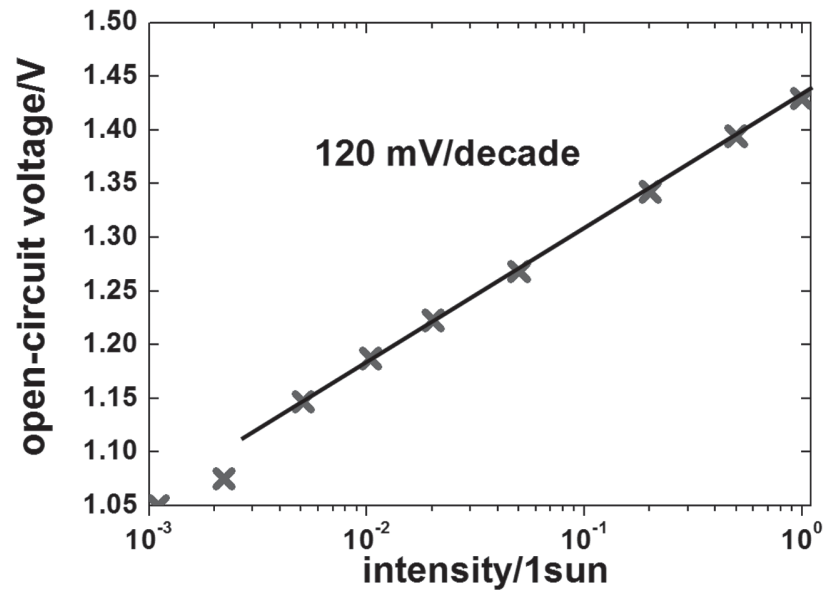

Figure 3. $V_{o c}$ as a function of illumination intensity provided by white LEDs. A value of 1 sun delivers a short-circuit current close to the one at $100 \mathrm{~mW} \mathrm{~cm}{ }^{-2}$ under simulated AM1.5.

molecular orbital (LUMO) of spiro-OMeTAD referred to the energy levels of $\mathrm{FAPbBr}_{3}$ and might be enhanced by dipoles formed at the interfaces. A further indication for the high selectivity is given by the fact that the $J-V$ curves for FA(2) devices (Figure 2) under illumination and in the dark do not show a pronounced point of intersection.

Biasing the device in forward and collecting the emitted photon flux of electrons and holes that radiatively recombine in the $\mathrm{FAPbBr}_{3}$, we measure an electroluminescence external quantum efficiency (EQE) of $\approx 10^{-8} \ldots 10^{-7}$ for currents of 5-10 $\mathrm{mA} \mathrm{cm}{ }^{-2}$. Considering the photovoltaic EQE onset (Figure S5, Supporting Information), we expect a photovoltage of $V_{\text {oc }}$ rad $-\Delta V_{\text {oc, nonrad. loss }}=2.0-0.5=1.5 \mathrm{~V}^{[33]}$ This rough estimation is in decent agreement with measured values of $V_{\text {oc }}$ close to $1.45 \mathrm{~V}$ for this device.

Such a significant improvement in photovoltage was further investigated by impedance spectroscopy (IS). The measurements based on impedance spectroscopy revealed a clear difference in the resistive response of FA(1) and FA(2) devices. With increasing forward voltage, both the resistances (determined at higher as well as lower frequency range) dropped faster for FA(1) device (Figure S6, Supporting Information). Relatively faster nonradiative recombination can explain a lower opencircuit voltage obtained from FA(1) devices. ${ }^{[31,34,35]}$

The reproducibility of our results is ascertained by depicting the photovoltaic efficiency derived from $J-V$ measurements for a batch of 20 devices (Figure S7, Supporting Information). Around $80 \%$ of the devices exhibited a photovoltage $>1.4 \mathrm{~V}$ under illumination of $100 \mathrm{~mW} \mathrm{~cm}{ }^{-2}$, further confirming excellent reproducibility of our results. It is worth mentioning that the photovoltage of $\mathrm{FAPbBr}_{3}$ devices remained remarkably stable upon prolonged storage under ambient conditions for more than 3 months (Figure S8, Supporting Information).

Due to the accumulation and migration of ions at various interfaces and within the perovskite solar cells, scan speed dependent hysteresis is observed in current-voltage curves. ${ }^{[36,37]}$ Arguably, hysteresis creates discrepancy in estimating the real photovoltaic parameters obtained from a $J-V$ curve. ${ }^{[38]}$ 

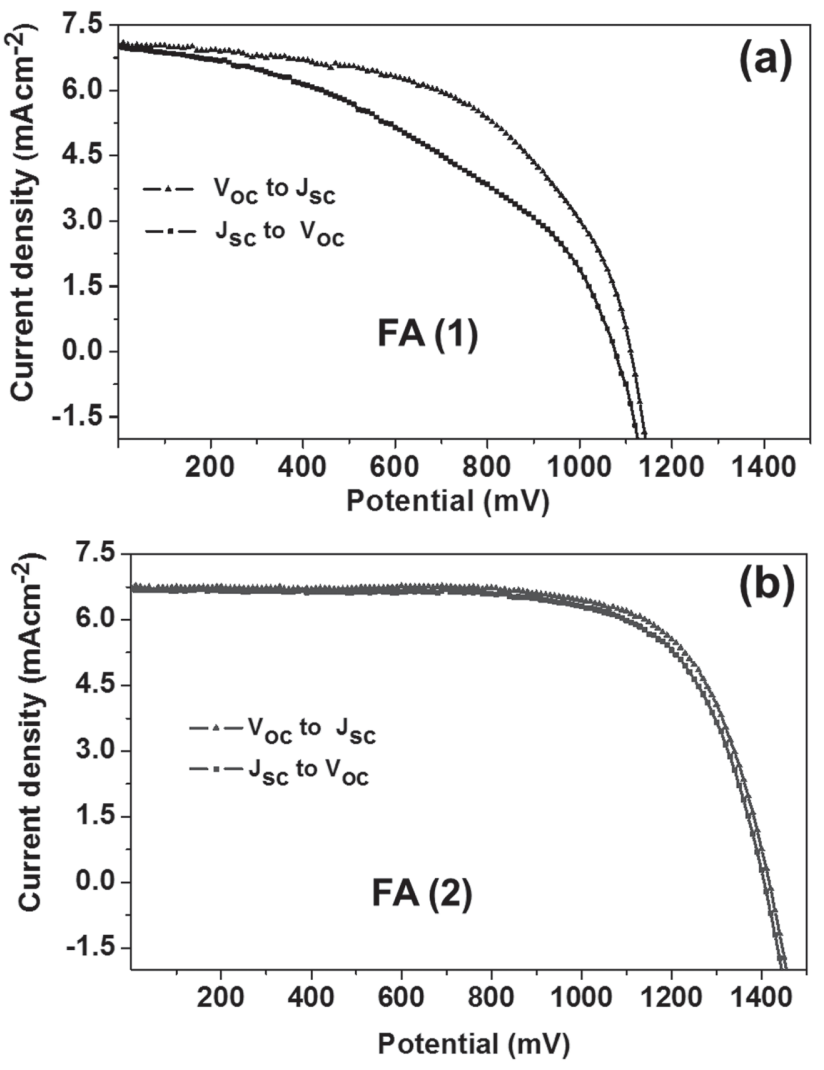

Figure 4. Current-voltage hysteresis recorded at a scan rate of $0.1 \mathrm{~V} \mathrm{~s}^{-1}$ under stimulated AM1.5 $100 \mathrm{~mW} \mathrm{~cm} \mathrm{~cm}^{-2}$ photon flux for a) $\mathrm{FA}(1)$ device and b) $\mathbf{F A ( 2 )}$ device.

Figure 4a,b shows the hysteresis curves obtained from FA(1) and $\mathbf{F A}(2)$ devices recorded at a scanning rate of $0.1 \mathrm{~V} \mathrm{~s}^{-1}$. FA(2) devices exhibited negligible hysteresis as compared to FA(1) devices; in fact the latter displayed a considerable degree of hysteresis. Various strategies have been adopted to fabricate hysteresis-free efficient devices. ${ }^{[13]}$ Surface passivation or minimizing the concentration of vacancies/traps has been surmised as one of the ways to bring down the degree of the hysteresis. ${ }^{[39]}$ Herein, we have achieved so by controlling the growth and formation of $\mathrm{FAPbBr}_{3}$ layer, which further emphasizes the importance of perovskite film formation.

Figure S5 in the Supporting Information shows external quantum efficiency spectra of FA(1) and FA(2) photovoltaic devices as a function of wavelength. EQE spectra reveal that the generation of photocurrent begins at $\approx 550 \mathrm{~nm}$, which is in agreement with the band gap of pure $\mathrm{FAPbBr}_{3}{ }^{12}$ and the current densities obtained from EQE data are in good agreement with $J_{\mathrm{sc}}$ values acquired from current-voltage measurements.

\subsection{Spectroscopic Studies}

\subsubsection{Absorption Studies}

Comparative analysis of photovoltaic studies of FA(1) and FA(2) devices showed that the former exhibits slightly higher current density (Figure 2a). Such an enhancement can be attributed to higher loading of $\mathrm{FAPbBr}_{3}$ perovskite in $\mathrm{FA}(1)$ films as confirmed by cross-sectional SEM analysis. To unravel the difference in short-circuit current densities further; we examined perovskite films with UV-visible absorption spectroscopy in transmission mode. Both FA(1) and FA(2) films showed a sharp absorption onset around $550 \mathrm{~nm}$ (Figure 5a) however, FA(1) film displayed higher absorbance. Higher absorption indicates relatively higher loading of $\mathrm{FAPbBr}_{3}$ which clearly rationalizes higher current density obtained from FA(1) devices.

\subsubsection{Photoluminescence Studies}

The formation of thicker films which expectedly exhibit higher absorption justifies the generation of higher photocurrent in FA(1) devices. To understand the cause of higher $V_{\text {oc }}$ in $\mathbf{F A}(2)$ devices, we performed time-integrated and time-resolved photoluminescence (TRPL) spectroscopy as the $V_{\text {oc }}$ in case of optimized contacts is determined by charge carrier dynamics and emission characteristics of the absorber. ${ }^{[40,41]}$

Figure $5 \mathrm{~b}$ shows the time-integrated PL spectra acquired at 15 and $300 \mathrm{~K}$ for $\mathbf{F A ( 1 )}$ and FA(2) perovskite films. At $300 \mathrm{~K}$, FA(2) exhibits stronger PL intensity ( $>8$ times) compared to FA(1) sample. As this difference could be due to various reasons, the PL signal is also measured at $15 \mathrm{~K}$, where nonradiative recombination channels are reduced. By comparing the PL intensity at $15 \mathrm{~K}$ (inset), which shows comparable values, we surmise that such a contrast in PL intensity at $300 \mathrm{~K}$ could arise from variations in the nonradiative recombination rates which are apparently lower in FA(2) sample. To gain further understanding of the kinetics of charge carrier decay, we investigated the samples through time-resolved photoluminescence. Figure $5 \mathrm{c}, \mathrm{d}$ presents the time-dependent PL decay traces for both FA(1) and FA(2) films recorded at $300 \mathrm{~K}$. FA(1) sample shows a two exponential decay with extremely short decay time components $\left(\tau_{1}=500 \mathrm{ps}\right.$ and $\left.\tau_{2}=2 \mathrm{~ns}\right)$ whereas the $\mathbf{F A}(2)$ sample exhibits a mono-exponential decay with a relatively long lifetime $\left(\tau_{1}=24 \mathrm{~ns}\right)$. From PL and TRPL studies we noticed that the FA(2) sample exhibits a lower nonradiative recombination rate and longer lasting charge carriers compared to $\mathbf{F A}(\mathbf{1})$ which could possibly explain the difference in $V_{\text {oc }}$ as shown in Figure 2. ${ }^{[40,41]}$

\subsubsection{Amplified Spontaneous Emission}

Amplified spontaneous emission measurements were carried out on $\mathbf{F A}(\mathbf{1})$ and $\mathbf{F A}(2)$ films after pumping them with 70 ps laser pulses with tunable wavelengths. ASE was fluently observed in both samples with wide range of pumping wavelengths $(430-530 \mathrm{~nm})$. Figure $6 \mathrm{a}, \mathrm{b}$ shows the evolution of emission spectra with increasing pump fluence of $450 \mathrm{~nm}$ laser excitation pulses. At low fluence, emission spectrum corresponding to SE centered at $\approx 550 \mathrm{~nm}$ was observed. However over pump fluence threshold, SE is accompanied with the appearance of a sharp peak (transition to ASE) on the lower 

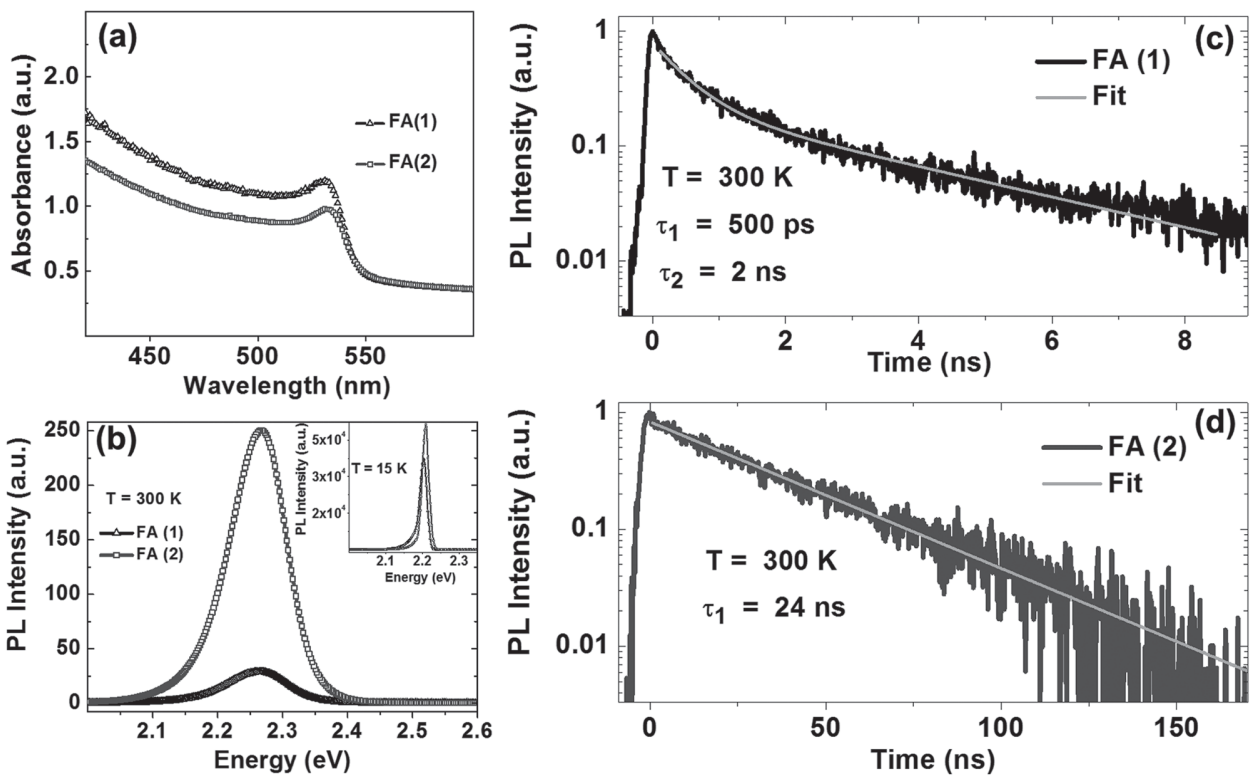

Figure 5. a) UV-visible absorbance spectra of FA(1) and FA(2) samples. b) Photoluminescence spectra of FA(1) and FA(2) at $300 \mathrm{~K}$. The inset shows the PL spectra at 15 K. c,d) Decays of PL intensity of FA(1) and FA(2) at $300 \mathrm{~K}$ in semi-logarithmic scale with exponential fitting.

energy side of the broad bands, centered at 557 and $560 \mathrm{~nm}$ for FA(1) and FA(2) samples, respectively.

FA(1) sample displays a slower ASE growth with increasing pump fluence, which makes it more difficult to define the threshold of ASE precisely. Using the two-segment method, ASE threshold of $\approx 615 \mu \mathrm{J} \mathrm{cm}^{-2}$ was estimated, which corresponds to a threshold carrier density of $\approx 7.5 \times 10^{18} \mathrm{~cm}^{-3}$. On the other hand, FA(2) sample showed a sharp transition from SE to ASE at a pump fluence of $190 \mu \mathrm{J} \mathrm{cm}^{-2}$ per pulse which corresponds to an ASE threshold carrier density of $\approx 2.3 \times 10^{18} \mathrm{~cm}^{-3}$ (Figure 6c). The absorbance spectrum, thickness and porosity of $\mathrm{mp}-\mathrm{TiO}_{2}$ layer were taken into account for estimating threshold carrier densities. The carrier density values are in agreement with the values reported for $\mathrm{MAPbI}_{3}$ perovskites, indicating that organic cation contributes marginally to the density of states in organic-inorganic lead halide perovskites.

Furthermore FA(2) sample shows a higher quantum efficiency (Figure 6c) (as can be deduced from the sharp slope in the linear region), whereas FA(1) sample suffers from a

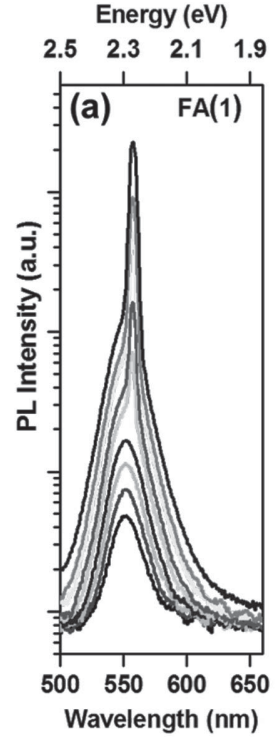

Energy (eV)
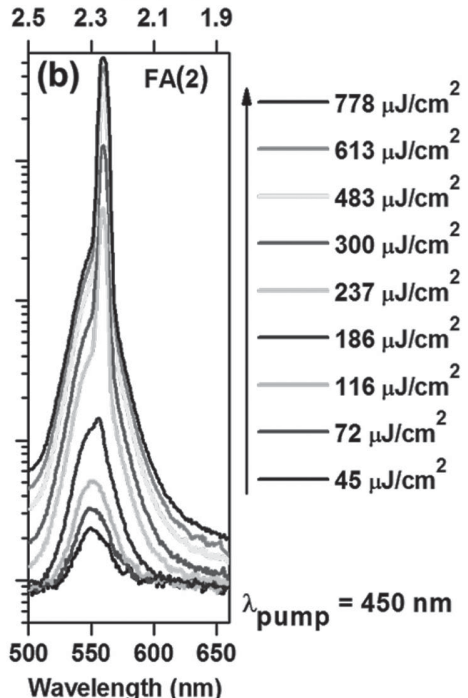

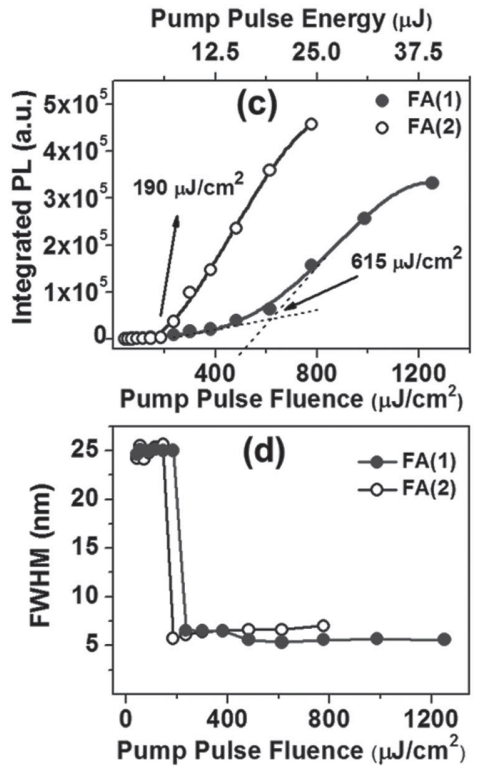

Figure 6. Evaluation of the PL spectra with increasing pump pulse fluence for a) FA(1) and b) FA(2) film. The $\gamma$-axes are of the same logarithmic scale for the two figures. c) Integrated PL intensity versus pump fluence for FA(1) (solid circles) and FA(2) (open circles) films showing, respectively, the ASE threshold at $615 \mu \mathrm{J} \mathrm{cm}$ /pulse and $190 \mu \mathrm{J} \mathrm{cm}^{-2} /$ pulse, and d) Evolution of FWHM with increasing pump fluence for FA(1) (solid circles) and FA(2) (open circles). 
reduced quantum efficiency, faster ASE saturation and lesser quantum yield. Such a strong contrast between the two samples clearly illustrates the importance of experimental conditions employed for the synthesis of $\mathrm{FAPbBr}_{3}$ perovskite to achieve desired electro-optical properties. This is not trivial as the realization of high performance in solar cells can be reflected in efficient ASE characteristics as well. Comparatively, FA(2) sample displayed better performance most likely because of lower nonradiative recombination rates which are also evident from PL studies. Therefore, we contend that growth and morphology of the perovskite structures considerably influence the nature and type of defects/traps which could affect their optical gain applications.

\section{Conclusion}

In summary, our work demonstrated the critical role of solvent in controlling the growth of $\mathrm{FAPbBr}_{3}$ perovskite structures. Morphological studies revealed that the surface coverage of the perovskite films remarkably improves when $\mathrm{PbBr}_{2}$ films are deposited from a stoichiometric mixture of DMF and DMSO solvents. To account for these findings, we surmise that besides the enhancement in solubility, employing a mixture of solvents slows down the growth of the lead halide structures during spin coating thus yielding a uniform film with complete surface coverage. The generation of smooth and uniform FA(2) films exhibiting stronger emission and longer charge carrier lifetime paved the way for the fabrication of solar cells exhibiting high $V_{\text {oc }}$ of $1.42 \mathrm{~V}$ and a negligible hysteresis. Arguably, devices based on $\mathrm{FA}(2) \mathrm{FAPbBr}_{3}$ films perform remarkably better owing to less shunting between $\mathrm{TiO}_{2}$ and spiro-OMeTAD, and reduced nonradiative losses. ASE studies on perovskite films showed that the FA(2) films themselves exhibit promising emission characteristics with a sharp transition from SE to ASE and a higher quantum yield along with a high quantum efficiency. Without any contextualization, we believe this work could lead to the fabrication of efficient $\mathrm{FAPbBr}_{3}$-based true green lasers in the future.

\section{Experimental Section}

Preparation of Photoanode and Device Fabrication: Prior to the deposition of $\mathrm{TiO}_{2}$ compact layer, the FTO substrate was cleaned by ultrasonication in Deconex $\left(0.2 \%\right.$ deionized $\left.\mathrm{H}_{2} \mathrm{O}\right)$ detergent, rinsed thoroughly with deionized water and ethanol, and then treated in a $\mathrm{UV} / \mathrm{O}_{3}$ cleaner for $15 \mathrm{~min}$. A dense $\mathrm{TiO}_{2}$ blocking layer of $\approx 30 \mathrm{~nm}$ thickness was deposited by aerosol spray pyrolysis on a cleaned TCO glass (NSG 10, Nippon sheet glass, Japan) at $450{ }^{\circ} \mathrm{C}$ using a commercial titanium diisopropoxide bis(acetylacetonate) solution (75\% in 2-propanol, Sigma-Aldrich) diluted in ethanol (1:9, volume ratio) as precursor and oxygen as carrier gas. To form the mesoporous layer, diluted paste (1:3.5 wt. ratio) (Dyesol 30NRD) was spin coated (5000 rpm, acceleration $2000 \mathrm{rpm}$ for $30 \mathrm{~s}$ ) onto the substrate containing $\mathrm{TiO}_{2}$ compact layer. This was followed by a series of sintering steps $\left(325{ }^{\circ} \mathrm{C}\right.$ for $5 \mathrm{~min}$ with $15 \mathrm{~min}$ ramp time, $375{ }^{\circ} \mathrm{C}$ for $5 \mathrm{~min}$ with $5 \mathrm{~min}$ ramp time, $450{ }^{\circ} \mathrm{C}$ for $15 \mathrm{~min}$ with $5 \mathrm{~min}$ ramp time, and $500{ }^{\circ} \mathrm{C}$ for 15 min with 5 min ramp time) in dry air.

Synthesis of $\mathrm{CH}\left(\mathrm{NH}_{2}\right)_{2} \mathrm{Br}$ : $\mathrm{CH}\left(\mathrm{NH}_{2}\right)_{2} \mathrm{Br}$ was synthesized by dropping slowly $15 \mathrm{~mL}$ of hydrobromide acid (48\% wt. in water) (Aldrich) into a solution of $5 \mathrm{~g}$ formamidine acetate (Sigma-Aldrich) in methanol cooled at $0{ }^{\circ} \mathrm{C}$. The solution was further stirred for $5 \mathrm{~h}$ at room temperature and then at $80^{\circ} \mathrm{C}$ for $30 \mathrm{~min}$. The clear solution was concentrated by rotary evaporation at $80{ }^{\circ} \mathrm{C}$ until no obvious liquid remained. Subsequently the crude solid was dissolved by a minimum amount of ethanol and reprecipitated in diethyl ether and filtered. The procedure was repeated three times and the resulting white solid was collected and dried at $80^{\circ} \mathrm{C}$ under vacuum for 2 days.

Deposition of $\mathrm{FAPbBr}_{3}$ Perovskite: All materials were purchased from Sigma-Aldrich or Acros Organics and were used as received. $\mathrm{FAPbBr}_{3}$ films were deposited using sequential deposition method. 1.2 M $\mathrm{PbBr}_{2}$ precursor solutions were prepared in DMF and DMSO by constant stirring at $60{ }^{\circ} \mathrm{C}$ for $30 \mathrm{~min}$. $\mathrm{PbBr}_{2}$ (DMF), $\mathrm{PbBr}_{2}$ (DMF+DMSO in 1:1 volume ratio) and $\mathrm{PbBr}_{2}$ (DMSO) solutions were spin coated onto the mesoporous $\mathrm{TiO}_{2}$ films at $3000 \mathrm{rpm}$ for $30 \mathrm{~s}$. This was followed by annealing the films at $80{ }^{\circ} \mathrm{C}$ for $15 \mathrm{~min}$. After cooling to room temperature, the films were dipped into isopropanol solution of $\mathrm{FABr}$ $\left(50 \times 10^{-3} \mathrm{M}\right)$ for $5 \mathrm{~min}$ at $60^{\circ} \mathrm{C}$, rinsed with 2-propanol for $5 \mathrm{~s}$ and dried at $80{ }^{\circ} \mathrm{C}$ for $30 \mathrm{~min}$.

Deposition of Hole Conductor and Device Fabrication: To complete the fabrication of devices, spiro-OMeTAD as HTM was deposited by spin coating $40 \mu \mathrm{L}$ of the prepared solution at $4000 \mathrm{rpm}$ for $30 \mathrm{~s}$. The HTM solution was prepared by dissolving $72.3 \mathrm{mg}\left(2,2^{\prime}, 7,7^{\prime}\right.$-tetrakis ( $N, N$-di$p$-methoxyphenylamine)-9,9-spirobifluorene) (spiro-OMeTAD), $\quad 17.5 \mu \mathrm{L}$ of a stock solution of $520 \mathrm{mg} \mathrm{mL}^{-1}$ bis(trifluoromethylsulphonyl)imide in acetonitrile, and $29 \mu \mathrm{L}$ of a stock solution of $300 \mathrm{mg} \mathrm{mL}^{-1} \operatorname{tris}(2-(1 \mathrm{H}$ pyrazol-1-yl)-4-tert-butylpyridine)cobalt(III) bis (trifluoromethylsulphonyl) imide in acetonitrile, and $28.8 \mu \mathrm{L}$ 4-tert-butylpyridine in $1 \mathrm{~mL}$ chlorobenzene. The device fabrication was carried out under controlled atmospheric conditions with humidity $<1 \%$. Finally, device fabrication was completed by thermally evaporating $70 \mathrm{~nm}$ of gold layer as a back contact.

Materials and Spectroscopic Characterization: XRD data were collected on a Bruker Advance D8 X-ray diffractometer with a graphite monochromator, using $\mathrm{Cu}-\mathrm{K} \alpha$ radiation, at a scanning rate of $0.5^{\circ} \mathrm{min}^{-1}$. An FESEM (Merlin) was employed to analyze the morphology of the samples. An electron beam accelerated to $3 \mathrm{kV}$ was used with an in-lens detector. The optical properties of perovskite films were studied using UV-visible absorption and fluorescence spectroscopy. The absorption spectra of perovskite films were recorded with a UV-vis-NIR spectrophotometer (CARY-5) in the transmission mode. To record photoluminescence spectra and PL decay kinetics, the samples were excited by the second harmonic of a picosecond modelocked Ti:Sapphire laser $(80.5 \mathrm{MHz})$. The excitation beam is focused on the sample by means of a $90 \mathrm{~mm}$ focal that allows for an excitation spot diameter of around $100 \mu \mathrm{m}$. The average power was kept in the range $1-10 \mathrm{~mW}$, which corresponds to $0.05-0.5 \mu \mathrm{Jm}^{-2}$ per pulse. The collected PL was spectrally and temporally analyzed using a $32 \mathrm{~cm}$ focal length monochromator equipped with a charge-coupled device (CCD) and a streak camera. Power-dependent PL and ASE studies were carried out using picosecond laser pulses generated using an optical parametric generator (OPG) that is pumped by a Q-switched picosecond $\mathrm{Nd}$ :Yag laser with a fundamental output of $1064 \mathrm{~nm}$, pulse duration of $70-80$ ps and repetition rate of $15 \mathrm{~Hz}$. The circular laser beam, after passing through the OPG, was focused using a biconvex lens to a diameter of $2 \mathrm{~mm}$.

Device Characterization: The current-voltage characteristics of the perovskite devices were recorded with a digital source meter (Keithley model 2400, USA). A $450 \mathrm{~W}$ xenon lamp (Oriel, USA) was used as the light source for photovoltaic $(U-V)$ measurements. The spectral output of the lamp was filtered using a Schott K113 Tempax sunlight filter (Präzisions Glas \& Optik $\mathrm{GmbH}$, Germany) to reduce the mismatch between the simulated and actual solar spectrum to less than $2 \%$. The photoactive area of $0.16 \mathrm{~cm}^{2}$ was defined using a dark-colored metal mask. Incident photon-to-current conversion efficiency (IPCE) measurements were made using a $300 \mathrm{~W}$ xenon light source (ILC Technology, USA). A double-monochromator spectrometer (Gemini-180, Jobin Yvon Ltd., UK) was used to select and increment the wavelength 
of the radiation impinging on the cells. The incident monochromatic light was passed through a chopper running at $1 \mathrm{~Hz}$ and the on/off ratio was measured by an operational amplifier. This was superimposed on a white light bias corresponding to an intensity of $10 \mathrm{~mW} \mathrm{~cm}$. IS, electroluminescence and intensity-dependent photovoltage measurements were performed by a Biologic SP300 (BioLogic, France). The measurements were performed with white light light emitting diodes (LEDs) with the intensity of about 1sun. IS measurements were carried out in a frequency range between $7 \mathrm{MHz}$ and $0.05 \mathrm{~Hz}$ for potentials between $0 \mathrm{~V}$ and about $V_{\text {oc }}$ (with a $20 \mathrm{mV}$ sinusoidal $A C$ perturbation) in $50 \mathrm{mV}$ steps. The resulting impedance spectra were analyzed with the ZView software (Scribner Associate).

\section{Supporting Information}

Supporting Information is available from the Wiley Online Library or from the author.

\section{Acknowledgements}

N.A. and M.I.D. contributed equally to this work. N.A. gratefully acknowledges the financial support from the Swiss confederation under Swiss Government Scholarship Programme. The authors acknowledge the European Community's Seventh Framework Programme (FP7/20072013) under grant agreement no. 281063 of the Powerweave project and no. 604032 of the MESO project for financial support. M.H. and A.A. gratefully acknowledge the financial support by the National Plan for Science, Technology and Innovation (MAARIFAH), King Abdulaziz City for Science and Technology, Kingdom of Saudi Arabia, Award Number (ENE1474-02).

Received: November 19, 2015 Revised: December 18, 2015 Published online:

[1] a) P. Gao, M. Grätzel, M. K. Nazeeruddin, Energy Environ. Sci. 2014, 7, 2448; b) J.-H. Im, C.-R. Lee, J.-W. Lee, S.-W. Park, N.-G. Park, Nanoscale 2011, 3, 4088.

[2] D. B. Mitzi, J. Chem. Soc., Dalton Trans. 2001, 1.

[3] A. Kojima, M. Ikegami, K. Teshima, T. Miyasaka, Chem. Lett. 2012, 41, 397.

[4] a) W. S. Yang, J. H. Noh, N. J. Jeon, Y. C. Kim, S. Ryu, J. Seo, S. I. Seok, Science 2015, 348, 1234; b) M. Ibrahim Dar, M. Abdi-Jalebi, N. Arora, T. Moehl, M. Grätzel, M. K. Nazeeruddin, Adv. Mater. 2015, 27, 7221.

[5] J. Luo, J.-H. Im, M. T. Mayer, M. Schreier, M. K. Nazeeruddin, N.-G. Park, S. D. Tilley, H. J. Fan, M. Grätzel, Science 2014, 345, 1593.

[6] M. Schreier, L. Curvat, F. Giordano, L. Steier, A. Abate, S. M. Zakeeruddin, J. Luo, M. T. Mayer, M. Grätzel, Nat. Commun. 2015, 6, 7326 .

[7] S. Ryu, J. H. Noh, N. J. Jeon, Y. Chan Kim, W. S. Yang, J. Seo, S. I. Seok, Energy Environ. Sci. 2014, 7, 2614.

[8] G. E. Eperon, S. D. Stranks, C. Menelaou, M. B. Johnston, L. M. Herz, H. J. Snaith, Energy Environ. Sci. 2014, 7, 982.

[9] A. Kojima, K. Teshima, Y. Shirai, T. Miyasaka, J. Am. Chem. Soc. 2009, 131, 6050

[10] E. Edri, S. Kirmayer, D. Cahen, G. Hodes, J. Phys. Chem. Lett. 2013, 4,897

[11] J. H. Heo, D. H. Song, S. H. Im, Adv. Mater. 2014, 26, 8179.
[12] F. C. Hanusch, E. Wiesenmayer, E. Mankel, A. Binek, P. Angloher, C. Fraunhofer, N. Giesbrecht, J. M. Feckl, W. Jaegermann, D. Johrendt, T. Bein, P. Docampo, J. Phys. Chem. Lett. 2014, 5, 2791.

[13] N. J. Jeon, J. H. Noh, Y. C. Kim, W. S. Yang, S. Ryu, S. I. Seok, Nat. Mater. 2014, 13, 897.

[14] R. Sheng, A. Ho-Baillie, S. Huang, S. Chen, X. Wen, X. Hao, M. A. Green, J. Phys. Chem. C 2015, 119, 3545.

[15] M. F. Aygüler, M. D. Weber, B. M. D. Puscher, D. D. Medina, P. Docampo, R. D. Costa, J. Phys. Chem. C 2015, 119, 12047.

[16] F. Deschler, M. Price, S. Pathak, L. E. Klintberg, D.-D. Jarausch, R. Higler, S. Hüttner, T. Leijtens, S. D. Stranks, H. J. Snaith, M. Atatüre, R. T. Phillips, R. H. Friend, J. Phys. Chem. Lett. 2014, 5, 1421.

[17] K. Chen, A. J. Barker, F. L. C. Morgan, J. E. Halpert, J. M. Hodgkiss, J. Phys. Chem. Lett. 2015, 6, 153.

[18] S. D. Stranks, G. E. Eperon, G. Grancini, C. Menelaou, M. J. P. Alcocer, T. Leijtens, L. M. Herz, A. Petrozza, H. J. Snaith, Science 2013, 342, 341.

[19] G. Xing, N. Mathews, S. Sun, S. S. Lim, Y. M. Lam, M. Grätzel, S. Mhaisalkar, T. C. Sum, Science 2013, 342, 344.

[20] M. Saba, M. Cadelano, D. Marongiu, F. Chen, V. Sarritzu, N. Sestu, C. Figus, M. Aresti, R. Piras, A. Geddo Lehmann, C. Cannas, A. Musinu, F. Quochi, A. Mura, G. Bongiovanni, Nat. Commun. 2014, 5, 5049 .

[21] G. Xing, N. Mathews, S. S. Lim, N. Yantara, X. Liu, D. Sabba, M. Grätzel, S. Mhaisalkar, T. C. Sum, Nat. Mater. 2014, 13, 476

[22] S. D. Stranks, S. M. Wood, K. Wojciechowski, F. Deschler, M. Saliba, H. Khandelwal, J. B. Patel, S. J. Elston, L. M. Herz, M. B. Johnston, A. P. H. J. Schenning, M. G. Debije, M. K. Riede, S. M. Morris, H. J. Snaith, Nano Lett. 2015, 15, 4935

[23] Q. Liao, K. Hu, H. Zhang, X. Wang, J. Yao, H. Fu, Adv. Mater. 2015, 27, 3405.

[24] G. E. Eperon, V. M. Burlakov, P. Docampo, A. Goriely, H. J. Snaith, Adv. Funct. Mater. 2014, 24, 151.

[25] a) M. I. Dar, N. Arora, P. Gao, S. Ahmad, M. Grätzel, M. K. Nazeeruddin, Nano Lett. 2014, 14, 6991. b) M. I. Dar, M. Abdi-Jalebi, N. Arora, M. Grätzel, M. K. Nazeeruddin, Adv. Energy Mater. 6, 2015, 1501358.

[26] Y. Tidhar, E. Edri, H. Weissman, D. Zohar, G. Hodes, D. Cahen, B. Rybtchinski, S. Kirmayer, J. Am. Chem. Soc. 2014, 136,13249

[27] Y. Wu, A. Islam, X. Yang, C. Qin, J. Liu, K. Zhang, W. Peng, L. Han, Energy Environ. Sci. 2014, 7, 2934.

[28] a) N. Ahn, D.-Y. Son, I.-H. Jang, S. M. Kang, M. Choi, N.-G. Park, J. Am. Chem. Soc. 2015, 137, 8696; b) W. Li, J. Fan, J. Li, Y. Mai, L. Wang, J. Am. Chem. Soc. 2015, 137, 10399.

[29] a) R. Schölin, M. H. Karlsson, S. K. Eriksson, H. Siegbahn, E. M. J. Johansson, H. Rensmo, J. Phys. Chem. C 2012, 116, 26300; b) W. H. Nguyen, C. D. Bailie, E. L. Unger, M. D. McGehee, J. Am. Chem. Soc. 2014, 136, 10996.

[30] J. H. Heo, S. H. Im, J. H. Noh, T. N. Mandal, C.-S. Lim, J. A. Chang, Y. H. Lee, H.-j. Kim, A. Sarkar, Md. K. Nazeeruddin, M. Gratzel, S. I. Seok, Nat. Photon. 2013, 7, 486.

[31] H.-S. Kim, I. Mora-Sero, V. Gonzalez-Pedro, F. Fabregat-Santiago, E. J. Juarez-Perez, N.-G. Park, J. Bisquert, Nat. Commun. 2013, 4, 2242.

[32] W. Tress, K. Leo, M. Riede, Appl. Phys. Lett. 2013, 102, 163901.

[33] U. Rau, Phys. Rev. B 2007, 76, 085303.

[34] A. Dualeh, T. Moehl, N. Tétreault, J. Teuscher, P. Gao, M. K. Nazeeruddin, M. Grätzel, ACS Nano 2014, 8, 362.

[35] E. J. Juarez-Perez, M. Wußler, F. Fabregat-Santiago, K. Lakus-Wollny, E. Mankel, T. Mayer, W. Jaegermann, I. Mora-Sero, J. Phys. Chem. Lett. 2014, 5, 680.

[36] W. Tress, N. Marinova, T. Moehl, S. M. Zakeeruddin, M. K. Nazeeruddin, M. Gratzel, Energy Environ. Sci. 2015, 8, 995.

[37] C. Eames, J. M. Frost, P. R. F. Barnes, B. C. O/'Regan, A. Walsh, M. S. Islam, Nat. Commun. 2015, 6, 7497. 
[38] H. J. Snaith, A. Abate, J. M. Ball, G. E. Eperon, T. Leijtens, N. K. Noel, S. D. Stranks, J. T.-W. Wang, K. Wojciechowski, W. Zhang, J. Phys. Chem. Lett. 2014, 5, 1511.

[39] Y. Shao, Z. Xiao, C. Bi, Y. Yuan, J. Huang, Nat. Commun. 2014, 5, 5784.
[40] W. Tress, N. Marinova, O. Inganäs, M. K. Nazeeruddin, S. M. Zakeeruddin, M. Graetzel, Adv. Energy Mater. 2015, 5, 1400812.

[41] K. Tvingstedt, O. Malinkiewicz, A. Baumann, C. Deibel, H. J. Snaith, V. Dyakonov, H. J. Bolink, Sci. Rep. 2014, 4, 6071. 